City University of New York (CUNY) CUNY Academic Works

1986

\title{
An Alternative View of Education for Deaf Children: Part II
}

Lil Brannon

New York University

Sue Livingston

CUNY La Guardia Community College

\section{How does access to this work benefit you? Let us know!}

More information about this work at: https://academicworks.cuny.edu/lg_pubs/84

Discover additional works at: https://academicworks.cuny.edu

This work is made publicly available by the City University of New York (CUNY).

Contact: AcademicWorks@cuny.edu 


\title{
An Alternative View of Education for Deaf Children: Part II
}

\author{
Lil Brannom and Sue Livingston
}

\begin{abstract}
How might deaf children acquire one of the primary goals of educationliteracy in English? This article suggests that literacy in English as well as knowledge of the English language can be acquired concomitantly through developmental reading and writing activities that reflect principles of first language acquisition if students bring to these activities relatable experiences which they have already linguistically represented. Such activities engage students in reading and writing where content and context support them in their attempts to actively understand and convey meaning in English. The end product of, rather than the prerequisite for, this meaningful reading and writing is competence in English.
\end{abstract}

$\mathbf{P}$ art I of this article [see American Annals of the Deaf, 130 (1) ] contends that in order for deaf children to become literate in English, they must first develop their capacities for meaning-making and meaning-sharing. These capacities will naturally evolve if deaf children are given opportunities to think and learn in classrooms where instruction is content-focused and where students are using a linguistic system that appears to best represent meaning for them-American Sign Language (ASL). Children participating in such exchanges of meaning become more competent as their minds fill with linguistically represented experiences.

Only after creating those experiences for themselves can these children become ready to learn how to read and write. However, since they are unfamiliar with English-the linguistic system which must be known in order to become literate-the question becomes: How should knowledge of English be acquired?

This article offers an explanation of learning the English language concomitantly with learning to read and write. The authors contend that deaf children can learn English through reading and writing if the acquisition of English is seen as a natural process and if reading and writing are viewed as interdependent processes which initially can be acquired, to some degree, without first knowing the exact auditory or signed form of English.

\section{NATURAL LANGUAGE ACQUISITION PROCESS}

For many teachers of deaf students, the notion that children can learn English through reading and writing runs counterintuitive. They might ask, "How can a child read or write who does not first know the vocabulary and syntax of English in either its oral or signed form?" The assumptions that underlie such a question come from a behaviorist view of how children learn in general.

Lil Brannon is Assistant Professor for the Program in English Education, Department of Communication Arts and Science at New York University, and Sue Livingston is Assistant Professor in the Communication Skills Department at LaGuardia Community College, Long Island City, NY.

With respect to learning English, a behaviorist might argue that a deaf child needs a sequential English language curriculum where one skill builds on another, from the learning of vocabulary to the comprehension or construction of linked sentences. Such a curriculum is orderly; the teacher directs the skills to be mastered (presumably from simple to complex) and monitors a child's progress, checking correct demonstration of one skill before proceeding to the next level of difficulty. Yet research into the language acquisition of hearing children has shown the inadequacy of the assumptions governing a behaviorist perspective (Bruner, 1968; Chomsky, 1972).

A child does not receive a language at the discretion of teachers or parents but rather acquires a language while making sense of his or her world. Since there is no one-toone relationship between individual words and individual things (a chair, for example, can be used to mean various manifestations of the things we would classify into a category called chair), children come to understand their world and come to be understood by others by developing concepts in language.

Children form concepts when they understand a person's meaning and they express their own meaning within a context that supports these shared exchanges by capitalizing on what is either known by or easily discernible from the environment of both speaker and hearer. Even very young children's single-word utterances (e.g., a call for mother) imply a shared meaning between speaker and hearer interpretable according to the context within which they are uttered. Language, then, is acquired when it is used within a supportive context for the purpose of sharing meaning.

Hearing children in an English speaking environment learn how to exchange meaning through the use of English by the age of 5 without being instructed in the English language. They do so because they are provided with supportive contexts in which they can acquire the concepts that English represents.

Deaf children, however, present a more complex problem. Deaf children who draw upon ASL to work out their linguistic relations with experience have, like hearing children, developed the human capacity to communicate through lan- 
guage and thereby the ability to make and share meaning through acts of symbolization. But these ways of symbolizing experience differ from the ways in which English symbolizes experience.

Since the acquisition of English is a goal in the development of literacy, deaf children must be able to make and share meaning through English expression. Although not an easy task, this may be accomplished if deaf children's acquisition of English is viewed as a natural language acquisition process similar to the way in which hearing children acquire English and deaf children acquire ASL. In other words, deaf children will acquire ASL and English in similar ways, reflective of the general principles of first language acquisition mentioned above. This implies that deaf children's knowledge of English, like their knowledge of ASL, should be tacitly acquired within a supportive context where children participate in activities that engage them in meaning-making and meaning-sharing.

As suggested in Part I of this article, however, English rendered through a manual coding of the language does not appear to be a viable means by which deaf children can acquire competence in English. Instead, the authors suggest that competence in English be acquired through developmental reading and writing activities that provide deaf children with supportive contexts within which they can actively attempt to understand and convey meaning from and through English.

The authors also suggest that ASL, deaf children's more viable linguistic symbol system as posited in Part I of this article, be used as part of the supportive context to clarify the meanings deaf children will encounter in print or compose in writing. It is the authors' contention that deaf children will begin to acquire the linguistic structure of English if they bring to reading and writing experiences which they have already linguistically represented (see Part I); if they are afforded supportive contexts; and if they repeatedly attempt to make meaning in English through reading and writing.

\section{ACQUIRING ENGLISH THROUGH READING AND WRITING}

In order for deaf children to acquire English through reading and writing, the meaning-making and meaning-sharing processes must be viewed as interdependent. What students can infer about English through their reading, they can use in their writing; the structures that students use when they write can be used to reinforce their understanding of what they read.

The acquisition of reading and writing begins when children bring to reading and writing minds filled with linguistically represented experiences. For reading, those experiences should be relatable to the experiences depicted in the particular stories they will encounter.

Reading begins when children are given opportunities to follow and remember a story line by either being told stories in sign (ASL) or by creating meaning from picture storybooks. English structure and vocabulary can begin to be inferred through reading when children's own stories or experiences are told to a teacher who records them in English for the children.

Concomitantly, writing experiences can be provided that parallel these reading experiences. Children can be provided with picture storybooks to caption or can caption their own picture stories. These experiences fulfill the tenets of learn- ing English through developmental activities since children are comprehending and communicating meanings while experiencing English in a supportive, albeit highly teacherdependent context.

In both these reading and writing activities, children participate in rich, whole linguistic activities that are understandable to them and thereby supportive because content is either clearly pictured and consistent with their prior experiences or generated by the children themselves in the telling of their own stories. What is crucially important for both these activities is the background knowledge provided. Without linguistically represented experiences to apply to other relatable experiences and to share with other people, reading and writing, and hence the acquisition of English, will be meaningless activities.

Learning English through reading and writing continues when children comprehend the words of authors other than themselves and start to make their own stories. Deaf children should read and be read full-length stories with accompanying pictures. Full-length stories give children the opportunity to use the plot as part of the supportive context from which to predict upcoming events. These predictions generate additional context with which to spur young readers to read until their predictions are either confirmed or denied. Stories that tell of similar events happening repeatedly make prediction easier and help move children through text in an easier manner. Clearly pictured texts also help children make meaning of a story. Early language learning requires a supportive context for meaning-making and sharing, and early reading requires this support as well.

For English structure to be tacitly inferred during reading, deaf children should be engaged in the content of their stories. This requires that interesting, fully realized stories-the same stories that engage young hearing readers when they are first learning to read-be used (as long as they are clearly pictured and relatable to the prior experiences of deaf readers). Ideas from stories with interesting content will have an impact on children, will become their own, and will soon emerge in some form in their English. As young hearing readers read and have stories read and re-read to them, so should deaf readers. Frequent re-readings provide practice and eventual independent access to English.

Dialogue journals-informal writing between the deaf child and the teacher-support the child's reading while demanding that the child communicate in English. By relating a personal experience to the teacher in writing, the child sees how English functions through his or her actual production of it. The teacher's response to the child is always content and context specific and thus is accessible to the child. The goal of this exercise is for the child to develop some fluency in English, rather than for the child to develop technical accuracy of expression. The child at this stage needs to feel that his or her English, although halting and highly ungrammatical, is being understood and that he or she can understand the teacher.

Since the teacher's English provides accurate English structures that convey meaning, the child is provided with a rich linguistic environment to draw from and emulate. While this activity demonstrates to the child the communicative dimension of writing, other activities can reinforce the child's production of English and his or her development of reading competence. Deaf children should be encouraged to write full-length stories similar to the ones they are reading 
(drawing upon their own personal experiences). They should keep logs of their observations, their readings, their questions, and their insights. Just as technical accuracy is overlooked in the dialogue journals, it should also be disregarded in these activities. The goal of writing experiences in this stage is to develop writers who feel their meanings are valued.

As deaf children learn more about English, their knowledge can become part of a supportive context for them. In other words, deaf children can begin to use their understanding of English to gain more indepth understanding of it. Stories with supportive pictures still should be used, but as students become more familiar with English, books with fewer pictures and more text might be used. Deaf students can be asked to interpret story context and content through reading instead of having it as readily accessible to them as it was in the previous level (illustrations and/or predictable occurrences). Again, it is important that the story be related to the child's previous experiences so that meaning can be made of the story.

When meaning breaks down, support from ASL should clarify the author's intent by connecting the author's meaning to the plot and the readers' experiences. Troublesome passages should be re-read, only when students are making meaning and understanding what they are reading can they simultaneously be acquiring the form or vehicle of that meaning.

Writing activities on this level should stress clarity of ideas, which also requires some technical facility. Teachers may notice, however, that children will pick up many technical features from their reading and will need little instruction. If instruction is needed, it should be conducted in a supportive way within the context of the student's own writing.
Clarity in writing can be developed when students begin to write to readers other than themselves and their trusted teachers. When a student writes to someone distant, he or she must provide more context for his or her ideas and more development of thought. The teacher, as a trusted adult, can show the student the sections in the text that might be confusing to a reader, but the teacher should instruct the student to revise the piece appropriately for the reader. Where a student's paper is confusing, the teacher might select one problematic area for instruction, rather than overwhelming the student with too much information. This writing-toothers project may be a story, a report of the student's experiences, an analysis of a story the child has read, and so on.

As deaf students become more competent in English, they will read and write through their naturally acquired knowledge of English. Therefore, rather than having to know English prior to learning how to read and write-as a means to an end-knowledge of English becomes the end itself with the reading and writing process as the means to it. This view recognizes that English acquisition, as language acquisition, should occur in supportive contexts where meaning is made and shared. Developmental reading and writing activities, such as those described in this article, give deaf students whole views of English from which to work out the specifics of the language. Given continued exposure to English through meaningful reading and writing, these specifics will eventually be part of their naturally acquired competence in English.

\section{REFERENCES}

Bruner, J. (1968). Toward a theory of instruction. New York: Norton Press.

Chomsky, N. (1972). Language and mind. New York: Harcourt Brace Jovanovich. 